\title{
The Bacillus firmus-Bacillus lentus Complex and pH 7.0 Variants of Some Alkalophilic Strains
}

\author{
By RUTH E. GORDON*† AND JEAN L. HYDE \\ Waksman Institute of Microbiology, Rutgers, The State University of New Jersey, \\ PO Box 759, Piscataway, New Jersey 08854, U.S.A.
}

(Received 15 July 1981; revised 21 September 1981)

\begin{abstract}
Variants capable of growth at $\mathrm{pH} 7.0$ were obtained from 174 alkalophilic strains (optimum $\mathrm{pH}$ 9.7) of the genus Bacillus by successive transfer on media with decreasing $\mathrm{pH}$ values. Nearly half of the pH 7.0 variants were like strains of the $B$. firmus $-B$. lentus complex. The remaining $\mathrm{pH} 7.0$ variants grew at $50^{\circ} \mathrm{C}$ and were assigned to two groups closely related to B. lentus.
\end{abstract}

\section{INTRODUCTION}

During a taxonomic study of the genus Bacillus, begun in 1936, continued until 1952 and then pursued sporadically until the present, 1625 strains were assembled in the collection of the late Dr N. R. Smith, U.S. Department of Agriculture (NRS Collection). In addition, strains from many investigators were received for identification, and a small percentage of these were kept, either for further study or because they belonged to species poorly represented in the NRS Collection. From 1936 to 1962, this collection acquired merely twelve strains of $B$. firmus, five of $B$. lentus and eight designated $B$. firmus $-B$. lentus intermediates. In 1962, these 25 strains were augmented by six of $B$. firmus, three of $B$. lentus and eight intermediates that were isolated from sea water or a salt marsh (Turner \& Jervis, 1968; Gordon et al., 1977). At the same time, two ATCC strains of B. firmus and two of B. lentus were acquired. Although these ATCC strains were replicates of NRS strains, they had been maintained under different conditions for a long time. For this reason they were treated as separate strains.

In 1970, we received for taxonomic examination a collection of alkalophilic strains of Bacillus species that had been isolated mainly from soil, dung and water and grew optimally at pH 9.7 (Aunstrup et al., 1972). Since some of the physiological tests for the identification of Bacillus species could not be performed at this high $\mathrm{pH}$ value (Gordon, 1981), the alkalophilic strains could not be compared with the descriptions of recognized species. By successive transfer on media with decreasing $\mathrm{pH}$ values, variants of the alkalophilic strains were obtained that would grow on media at $\mathrm{pH} 7.0$ and could, therefore, be compared with known strains. Among the first 105 variants examined, there were $27(26 \%)$ that resembled the 20 strains of $B$. firmus in our collection.

In the following report, $\mathrm{pH} 7.0$ variants of all the 162 alkalophilic strains received in 1970 and of 12 alkalophilic strains from other culture collections are described and compared with strains of the $B$. firmus $-B$. lentus complex.

\section{METHODS}

Strains. The strain numbers and sources of the alkalophilic isolates of Aunstrup et al. (1972) are listed in Table 1. Twelve alkalophilic reference strains are presented in Table 2 together with their history and the species name

† Present address: American Type Culture Collection, 12301 Parklawn Drive, Rockville, Maryland 20852, U.S.A. 
Table 1. Source and strain numbers of alkalophilic isolates

Source

Soil

Dung

Water

Lime pit of tannery

Compost

Horn meal

Air contaminants

Strain no.

NRS 1548

NRS 1554

ATCC 21522

ATCC 21591

ATCC 27557

NCIB 9218

NRRL B-3881

ATCC 21592

to 21596
Strain numbers

BB $3,10,16,16(1), 17$ to $22,24,25,49$; C 300 to $302,304,311$ to $314,323,324$, $334,335,337$ to $343,346,348,354$ to $358,360,372$ to $374,412,413$; PB $9,16,17$, $19,20,25,33,35,38(1), 38(2), 40,41$; SB $14 \mathrm{a}, 14 \mathrm{~b}, 37$; VB 3,5 to 7,11

BB 30, 31, 34 to 37,40 ; BC 4, 6, 8, 12 to 17 ; C $336,347,349,351$ to $353,364,366$ to $369,371,375,376,379 \mathrm{a}, 380 \mathrm{a}, 382 \mathrm{~b}, 384$ to 390,392 to $404,410,411$; SB 5; TB $2,4,10,13$ to $15,18,19$

BB $1,7,23,41,43,45$; C 350,377 ; SB 16 ; TB $6,11,12,16,17$

$\mathrm{BC} 1$ to $3,7,9$ to 11 ; $365,370,378,383$

C 303 ; PB 39; SB 32

TB 9

C 325,326 ; VB 1,2

Table 2. History of alkalophilic reference strains

Name when received, source, strain name or number

Bacillus alcalophilus Vedder (1934); T. Gibson, University of Edinburgh (967); NCTC 4553*; A. Vedder (1)

B. alcalophilus; T. Gibson (1021); NCTC 4554; A. Vedder (2)

B. alkalophilus; R. L. Gherna, ATCC; K. Horikoshi (221; soil) (Horikoshi, 1971)

B. alcalophilus subsp. halodurans Boyer et al. (1973); R. L. Gherna, ATCC; K. Horikoshi (A-59; soil)

B. alcalophilus subsp. halodurans; R. L. Gherna, ATCC; E. W. Boyer (NRRL B-3881*)

B. circulans Jordan; J. M. Shewan, NCIB; M. E. Chislett (RU 38) (Chislett \& Kushner, 1961)

Bacillus sp.; W. C. Haynes, U.S. Department of Agriculture; E. W. Boyer

Bacillus spp.; R. L. Gherna, ATCC; K. Horikoshi (A-40, 124-1, 169, 135, 27-1; soil)

* Designated the type strain by Boyer et al. (1973).

under which they were received. In addition, 46 strains of the B. firmus-B. lentus complex (Gordon et al., 1977) also served as reference strains.

Development of $p H 7.0$ variants. At intervals of 5 to $10 \mathrm{~d}$, the alkalophilic cultures were grown successively on soil extract agar (Gordon et al., 1973) at $\mathrm{pH} 9.0, \mathrm{pH} \mathrm{8.5,} \mathrm{pH} 8.0, \mathrm{pH} 7.5$ and $\mathrm{pH} 7.0$ [media at the higher $\mathrm{pH}$ values were prepared by the addition of a sterile solution of $1 \mathrm{M}$-sodium sesquicarbonate to the autoclaved media (Aunstrup et al., 1972)]. The resulting cultures were transferred monthly on soil extract agar (pH 7.0) for 6 months or more before they were examined for their microscopic appearance and physiological reactions. In a few instances, growth and viability were enhanced by the addition of $3 \%(\mathrm{w} / \mathrm{v}) \mathrm{NaCl}$ to the soil extract agar.

Properties examined. The media and methods described by Gordon et al. $(1973,1977)$ were used in this study, with the following modifications.

Sporulation. If a culture on soil extract agar did not sporulate after $3 \mathrm{~d}$ to $7 \mathrm{~d}$ incubation, it was grown on soil extract agar with $3 \%(\mathrm{w} / \mathrm{v}) \mathrm{NaCl}$ and/or on soil extract yeast agar and re-examined. Soil extract yeast agar, a modification of the medium of Gounot (1967), contained: Difco yeast extract, $1 \mathrm{~g}$; dibasic potassium phosphate, $0.2 \mathrm{~g}$; agar, $15 \mathrm{~g}$; soil extract, $1000 \mathrm{ml}(\mathrm{pH} \mathrm{7.0)}$. The soil extract was prepared by autoclaving $500 \mathrm{~g}$ of air-dried, sifted garden soil with $500 \mathrm{ml}$ of tap water in a 21 flask for $30 \mathrm{~min}$, with the same precautions as used in preparing soil extract agar (Gordon et al., 1973). The cooled supernatant was carefully decanted, filtered through paper and made up to $500 \mathrm{ml}$ with tap water.

Temperature of incubation. Unless stated otherwise, strains whose maximum temperature for growth was $45^{\circ} \mathrm{C}$ or higher were incubated at $37^{\circ} \mathrm{C}$; other strains were incubated at $28^{\circ} \mathrm{C}$.

Anaerobic growth. Because BBL dehydrated anaerobic agar without glucose or $E_{\mathrm{h}}$ indicator (Gordon et al., 1973) was no longer available, BBL thioglycollate fluid medium (without glucose or $E_{\mathrm{h}}$ indicator) with $1.5 \%(\mathrm{w} / \mathrm{v})$ agar was substituted. If a culture, inoculated from one in nutrient broth, failed to grow aerobically on this medium, the test was repeated with an inoculum of a culture grown in nutrient broth containing $3 \%(w / v) ~ N a C l$. 
Maximum temperature for growth. Slants of soil extract agar with and without $3 \%(\mathrm{w} / \mathrm{v}) \mathrm{NaCl}$ were used for determining growth at the various temperatures. Growth on one or both of the agars was recorded as positive.

Acid production from carbohydrates. In addition to nutrient agar with $3 \%(\mathrm{w} / \mathrm{v}) \mathrm{NaCl}$ and $0.008 \%(\mathrm{w} / \mathrm{v})$ phenol red, basal ammonium phosphate agar with $3 \%(\mathrm{w} / \mathrm{v}) \mathrm{NaCl}$ and $0.0008 \%(\mathrm{w} / \mathrm{v})$ bromocresol purple [ $20 \mathrm{ml}$ of a $0.04 \%(w / v)$ solution per litre] served as a base for each carbohydrate. Because some cultures formed enough alkali from organic nitrogen in nutrient agar to neutralize the acid from some of the carbohydrates, cultures on the nutrient agar substrate were observed at 1, 2, 3, 5, 7, 10,14, 21 and $28 \mathrm{~d}$. Cultures on the ammonium phosphate substrate were observed at $7,14,21$ and $28 \mathrm{~d}$. Acid production from a carbohydrate in one or both of the substrate agars during incubation was recorded as positive.

Sensitivity to bacteriophage. If a culture failed to grow on the plates of nutrient agar used for demonstrating lysis by the bacteriophage for B. firmus ATCC 14575, the test was repeated on soil extract agar. All plates were incubated at $28^{\circ} \mathrm{C}$ and observed at 1,2 and $3 \mathrm{~d}$.

Formation of urease. The substrate broth was adjusted to $\mathrm{pH} 6.5$ before sterilization. All cultures were incubated at $28^{\circ} \mathrm{C}$ and examined at 7 and $14 \mathrm{~d}$ for an alkaline colour in the tubes containing urea relative to the control tubes.

Deamination of phenylalanine. Cultures on phenylalanine agar were tested for phenylpyruvic acid (Gordon et al., 1973) after 14 and $21 \mathrm{~d}$ incubation.

\section{RESULTS}

Lyophilized cultures of the alkalophilic isolates received for this study (Table 1) were

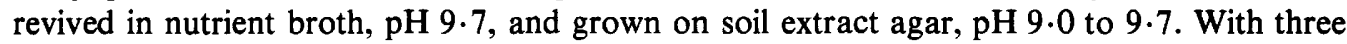
exceptions (strains C 351, 364, 378), the cultures were Gram-positive; all but eight (BB 36; C 351, 358, 360, 372, 374, 383, 413) were motile; and all but 11 (BB 45; BC 3, 7; C 371, 400; SB 14a, 14b, 16; TB 17; VB 3, 5) sporulated.

Examination of the variants of these 162 alkalophilic isolates and of the 12 alkalophilic reference strains, all of which grew and were maintained for five to eight years on media at $\mathrm{pH} 7 \cdot 0$, resulted in their assignment to the B. firmus-B. lentus complex (Tables 3 and 4). Re-examination of the 46 reference strains of this complex (Gordon et al., 1977) by the modified tests used in this study placed two strains (NRS 1569 and 1573) of the 18 previously designated as $B$. firmus $-B$. lentus intermediates within $B$. lentus, and the spectrum-like arrangement of the remaining 16 intermediate strains was similar to that reported previously (Gordon et al., 1977).

Among the $\mathrm{pH} 7.0$ variants of 174 alkalophilic strains, $B$. firmus was represented by 47 (27\%), including ATCC 21592, 21593 and 21596 (Tables 3 and 4). The microscopic appearance of these variants was more uniform than that of the other groups of variants. The rods were 0.7 to $0.9 \mu \mathrm{m}$ in width, and those of 37 of the cultures appeared singly, in pairs or in short chains. Their appearance is compared with that of strains of $B$. firmus and B. lentus in Fig. $1(a-d)$. Cultures of the remaining 10 variants also contained long chains and filaments like those illustrated in Fig. $1(e, f)$, and three of the 10 had many shadow, or poorly stained forms. Sporulation was not observed in 11 strains (BC 2, 8; C 387, 400; PB 20, 38(1); SB 14a, 14b, 16; VB 3, 5). Cultures of the remaining 36 strains formed central, subterminal or terminal ellipsoidal spores, which swelled the sporangia slightly if at all (Fig. 1).

Of the pH 7.0 variants, 17 were assigned as intermediates between $B$. firmus and $B$. lentus on the basis of their formation of acid from seven carbohydrates and by their sensitivity to bacteriophage for the type strain of B. firmus (Table 5). Intermediate pH 7.0 variants that had the same reactions as reference intermediate strains for the seven carbohydrates and to the bacteriophage were BC 7 (same as NRS 1562); C 325, 373, 403, 413, PB 38(2), ATCC 21591, NCIB 9218 (NRS 1148); and NRS 1554 (NRS 1565). The rods formed by the 17 intermediate variants were 0.7 to $1.0 \mu \mathrm{m}$ in diameter and appeared singly, in pairs or in short chains. Three of the variants (BC 4,7,10) did not sporulate. The ellipsoidal, subterminal and terminal spores of six cultures [C 325, 403, 413; PB 38(2); NCIB 9218; ATCC 21591] definitely swelled the sporangia, while sporangia of the remaining eight cultures were slightly swollen by their central and subterminal spores. 
Table 3. Some physiological properties of strains of the B. firmus-B. lentus complex

\begin{tabular}{|c|c|c|c|c|c|c|c|c|}
\hline & & & & \multicolumn{5}{|c|}{$\mathrm{pH} 7.0$ variants of alkalophilic strains } \\
\hline & \multicolumn{3}{|c|}{ NRS and ATCC reference strains* } & \multirow[b]{2}{*}{ B. firmus } & \multirow[b]{2}{*}{ Intermediates } & \multicolumn{3}{|c|}{$B$. lentus groups } \\
\hline & B. firmus & Intermediates & B. lentus & & & 1 & 2 & 3 \\
\hline $\begin{array}{l}\text { No. of strains ... } \\
\text { Property }{ }^{\dagger}\end{array}$ & 20 & 16 & 10 & 47 & 17 & 18 & 17 & 75 \\
\hline Hydrolysis of hippurate & 80 & 31 & 80 & 0 & 59 & 28 & 100 & 100 \\
\hline Growth in $7 \% \mathrm{NaCl}$ & 95 & 81 & 80 & 100 & 100 & 100 & 100 & 100 \\
\hline \multicolumn{9}{|l|}{ Utilization of: } \\
\hline Citrate & 5 & 31 & 10 & 4 & 24 & 44 & 100 & 100 \\
\hline Propionate & 0 & 13 & 0 & 0 & 0 & 28 & 88 & 69 \\
\hline Growth at $50^{\circ} \mathrm{C}$ & 0 & 0 & 0 & 0 & 6 & 0 & 100 & 100 \\
\hline \multicolumn{9}{|l|}{ Acid from: } \\
\hline Arabinose & 0 & 0 & 100 & 0 & 12 & 100 & 100 & 100 \\
\hline Glucose & 100 & 100 & 100 & 100 & 94 & 100 & 100 & 100 \\
\hline Mannitol & 90 & 100 & 100 & 89 & 88 & 94 & 100 & 100 \\
\hline Mannose & 0 & 69 & 100 & 0 & 65 & 100 & 100 & 100 \\
\hline Melibiose & 0 & 50 & 100 & 0 & 35 & 100 & 100 & 100 \\
\hline Raffinose & 0 & 56 & 100 & 0 & 35 & 100 & 100 & 100 \\
\hline Sorbitol & 0 & 6 & 30 & 0 & 12 & 56 & 82 & 0 \\
\hline Sucrose & 100 & 100 & 100 & 100 & 94 & 100 & 100 & 100 \\
\hline Xylose & 0 & 31 & 100 & 0 & 41 & 100 & 100 & 100 \\
\hline Sensitivity to bacteriophage & 100 & 31 & 0 & 100 & 88 & 0 & 0 & 100 \\
\hline \multicolumn{9}{|l|}{ Decomposition of: } \\
\hline Casein & 100 & 94 & 30 & 91 & 76 & 83 & 94 & 91 \\
\hline Gelatin & 90 & 94 & 40 & 79 & 65 & 94 & 100 & 100 \\
\hline Tyrosine & 15 & 13 & 0 & 0 & 0 & 0 & 0 & 0 \\
\hline Production of urease & 0 & 13 & 60 & 0 & 6 & 0 & 0 & 0 \\
\hline \multicolumn{9}{|l|}{ Reduction of nitrate } \\
\hline to nitrite & 65 & 13 & 40 & 0 & 18 & 0 & 94 & 3 \\
\hline \multicolumn{9}{|l|}{ Deamination of } \\
\hline phenylalanine & 85 & 19 & 20 & 100 & 35 & 6 & 0 & 1 \\
\hline
\end{tabular}

* Strains described by Gordon et al. (1977).

$\dagger$ Positive properties of all strains were: formation of catalase, hydrolysis of starch and growth at $35^{\circ} \mathrm{C}$. Negative properties were: production of acetoin and dihydroxyacetone, anaerobic growth, egg-yolk reaction, growth in Sabouraud dextrose broth and agar and resistance to lysozyme.

Table 4. Assignment of $p H 7.0$ variants of alkalophilic strains to groups of the $B$. firmus $-B$. lentus complex

No. of
strains

$$
\text { B. firmus }
$$

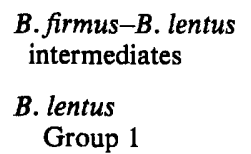

Group 2

Group 3

\section{Strain numbers}

BB $20,22,24,40$; BC 1, 2, 8; C $324,326,338,340,342,343,346$ to $350,352,353,355,379 \mathrm{a}, 387,395,399$ to 402,404 ; PB 20, 33, 35, $38(1), 39$; SB 14a, 14b, 16, 37; VB 1 to $3,5,6,11$; ATCC 21592 , 21593, 21596

BB 16; BC 3, 4, 7, 10; C 325, 373, 403, 413; PB 9, 19, 38(2); ATCC 21591, 21594; NCIB 9218; NRS 1548, 1554

BB 45; C 301, 302, 304, 311, 323, 334 to $337,339,341,368,369,392$; PB 25; SB 5; ATCC 21595

BB 3, 7, 23, 30; C 300, 303, 312 to $314,360,365,372,374$; SB 32 ; TB 13; VB 7; ATCC 21522

BB $1,10,16(1), 17$ to $19,21,25,31,34$ to $37,41,43,49$; BC $6,9,11$ to 17 ; C $351,354,356$ to $358,364,366,367,370,371,375$ to 378 , $380 \mathrm{a}, 382 \mathrm{~b}, 383$ to 386,388 to $390,393,394,396$ to 398,410 to 412; PB 16, 17, 40, 41; TB 2, 4, 6, 9 to 12,14 to 19; ATCC 27557; NRRL B-3881 

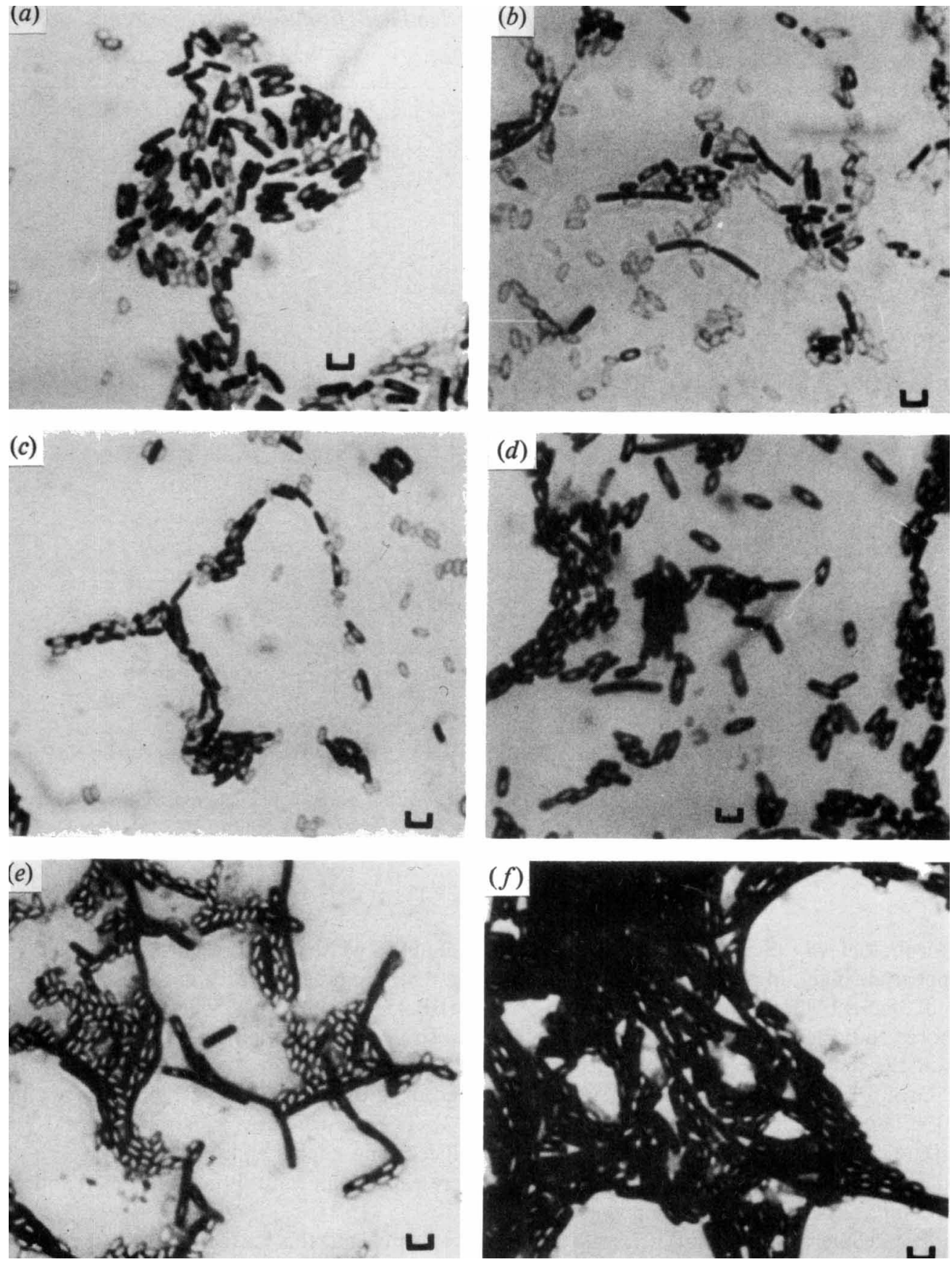

Fig. 1. Cells and sporangia of cultures grown on soil extract agar for $3 \mathrm{~d}$ at $28^{\circ} \mathrm{C}:(a) \mathrm{pH} 7.0$ variant of alkalophilic strain C 338 assigned to B. firmus; (b) ATCC 14575, type strain of $B$. firmus; (c) pH 7.0 variant of strain C 304 assigned to $B$. lentus Group 1; (d) ATCC 10840, type strain of $B$. lentus; $(e, f)$ pH 7.0 variants of strains C 374 and 300 assigned to B. lentus Group 2. The bar markers represent 2 $\mu \mathrm{m}$.

The $110 \mathrm{pH} 7.0$ variants representing $B$. lentus were divided into three groups by growth at $50{ }^{\circ} \mathrm{C}$, sensitivity to bacteriophage and reduction of nitrate to nitrite (Table 3 ). Of the three groups, the 18 strains of Group 1 were most like the reference strains of $B$. lentus. 
Table 5. Reactions of $p H 7.0$ variants assigned to the B. firmus-B. lentus intermediates

\begin{tabular}{|c|c|c|c|c|c|c|c|c|c|c|c|c|c|c|c|}
\hline \multirow[b]{2}{*}{ Strain } & \multicolumn{7}{|c|}{ Acid production from carbohydrates* } & \multicolumn{8}{|c|}{ Other properties $\dagger$} \\
\hline & Ara & Man & Mel & Raf & Sor & Suc & $\mathrm{Xyl}$ & SB & $\mathrm{C}$ & $\mathrm{G}$ & $\mathrm{U}$ & $\mathbf{N}$ & $\mathbf{P}$ & $\mathrm{H}$ & $50^{\circ} \mathrm{C}$ \\
\hline Typical $B$. firmus & - & - & - & - & - & + & - & + & + & $\mathrm{b}$ & - & $\mathrm{b}$ & + & - & - \\
\hline BB 16 & - & - & - & - & - & + & + & + & + & + & - & - & + & - & - \\
\hline BC 3 & - & - & - & - & - & + & + & + & + & + & - & - & + & - & - \\
\hline BC 4 & - & - & - & - & - & + & + & + & + & + & - & - & + & + & + \\
\hline PB 9 & - & - & - & - & - & - & - & $\mathbf{v}$ & + & + & + & + & - & + & - \\
\hline C 325 & - & + & - & - & - & + & - & + & + & + & - & - & - & + & - \\
\hline C 373 & - & + & - & - & - & + & - & + & + & + & - & + & - & + & - \\
\hline C 403 & - & + & - & - & - & + & - & + & - & - & - & - & - & + & - \\
\hline C 413 & - & + & - & - & - & + & - & + & - & - & - & - & - & + & - \\
\hline PB 38(2) & - & + & - & - & - & + & - & + & + & - & - & - & - & + & - \\
\hline ATCC 21591 & - & + & - & - & - & + & - & + & + & - & - & - & - & + & - \\
\hline NCIB 9218 & - & + & - & - & - & + & - & + & - & + & - & - & - & + & - \\
\hline PB 19 & - & - & + & + & - & + & - & + & + & + & - & - & + & + & - \\
\hline BC 7 & - & + & + & + & - & + & - & - & + & + & - & - & - & - & - \\
\hline NRS 1548 & - & + & + & + & - & + & + & + & + & + & - & - & + & - & - \\
\hline NRS 1554 & - & + & + & + & - & + & + & - & + & + & - & - & + & - & - \\
\hline BC 10 & + & - & + & + & + & + & + & + & + & - & - & + & - & - & - \\
\hline ATCC 21594 & + & + & + & + & + & + & + & $\mathbf{v}$ & - & - & - & - & - & - & - \\
\hline Typical B. lentus & & & & & & & & & & & & & & & \\
\hline Group 1 & + & + & + & + & $\mathrm{b}$ & + & + & - & b & $\mathrm{b}$ & b & b & - & b & - \\
\hline Group 2 & + & + & + & + & $\mathrm{b}$ & + & + & - & + & + & - & + & - & + & + \\
\hline Group 3 & + & + & + & + & - & + & + & + & + & + & - & - & - & + & + \\
\hline
\end{tabular}

$\mathrm{b}$, Some strains of the taxon were positive and others negative; $v$, cultures of the same strain were sometimes positive and sometimes negative.

- Ara, arabinose; Man, mannose; Mel, melibiose; Raf, raffinose; Sor, sorbitol; Suc, sucrose; Xyl, xylose.

$\uparrow \mathrm{SB}$, sensitive to bacteriophage for $B$. firmus ATCC 14575; C, decomposition of casein; G, decomposition of gelatin; $\mathrm{U}$, production of urease; $\mathrm{N}$, reduction of nitrate to nitrite; $\mathrm{P}$, deamination of phenylalanine; $\mathrm{H}$, hydrolysis of hippurate; $50^{\circ} \mathrm{C}$, growth at $50^{\circ} \mathrm{C}$.

Morphologically their rods varied from 0.6 to $0.9 \mu \mathrm{m}$ in width, and those of half the cultures appeared singly, in pairs and in short chains (Fig. 1c); the other cultures grew in long chains and filaments. Four of these pH 7.0 variants (BB 45; C 323, 337, 369) did not produce spores, and the central and subterminal ellipsoidal spores of the remaining 14 cultures did not swell the sporangia appreciably.

Group $2 \mathrm{~B}$. lentus strains could be distinguished from those of Group 1 by their growth at $50{ }^{\circ} \mathrm{C}$ and reduction of nitrate to nitrite (Table 3). The rods of these 17 strains were 0.7 to $1.0 \mu \mathrm{m}$ wide, and eight of the cultures also produced long chains and filaments (Fig. $1 e, f$ ). All but one strain (C 365) formed spores that were ellipsoidal, central or subterminal and did not noticeably swell the sporangia.

The cellular morphology of Group 3 strains was similar to that of the Group 2 strains but the cultures grew at $50^{\circ} \mathrm{C}$ and were sensitive to the bacteriophage. Nine of these $\mathrm{pH} 7.0$ variants (BB 37, 41, 43; BC 15, 17; C 412; TB 11, 12, 19) did not produce spores. The ellipsoidal, central and subterminal spores of $15 \%$ of the cultures of the remaining strains did not swell the sporangia while spores of the other $85 \%$ of the cultures swelled the sporangia slightly, but the free spores were no wider than the rods.

The specificity of the bacteriophage used in this study for strains of the B. firmus $-B$. lentus complex was examined by testing representative strains of a number of species. In addition to the sensitivity or resistance of the 220 strains recorded in Table 3, 402 strains representing $B$. subtilis, $B$. pumilus, $B$. licheniformis and ten other species were resistant to the bacteriophage. 
Of the 51 strains representing species incertae sedis (Gordon et al., 1973), 47 were resistant. The four phage-sensitive strains were ATCC 12905 (designated $B$. macroides), ATCC 14574 (B. badius), NRS 1117 (B. epiphytus), and NRS 1118 (B. filicolonicus).

\section{DIS C USSION}

The sensitivity to acid of strains of the $B$. firmus $-B$. lentus complex indicates that some of them might have their counterparts among the $\mathrm{pH} 7.0$ variants of alkalophilic strains of the genus. According to our tests and observations, strains of $B$. firmus, $B$. lentus and a number resembling previously designated intermediate strains appeared among the variants (Table 5). The strains that grew at $50^{\circ} \mathrm{C}$, assigned here to B. lentus Groups 2 and 3, were not matched by previously studied strains, although the overall pattern of their properties (Table 3 ) was like that of the NRS and ATCC strains of the B. firmus-B. lentus complex.

After thorough investigation, the utilization in the classification of the genus Bacillus of properties independent of the metabolism of the strains, i.e. DNA homology (Priest, 1981), lipid composition (Minnikin \& Goodfellow, 1981) and pyrolysis gas-liquid chromatography (O'Donnell \& Norris, 1981), is expected to be very valuable. If study of these and other strains by different methods confirms the four groupings made here and sharply reduces the number of $B$. firmus $-B$. lentus intermediates, the recognition of three or four different species may be justified. With our present knowledge of these strains, however, we prefer to place them loosely in the $B$. firmus-B. lentus complex.

We regret that time did not permit re-examination of the strains representing species incertae sedis in the NRS Collection, particularly of the four that were sensitive to the bacteriophage for B. firmus ATCC 14575.

After five to eight years of cultivation on agar at $\mathrm{pH} 7 \cdot 0$, cultures of some of the $\mathrm{pH} 7.0$ variants sporulated abundantly (Fig. 1) and might be expected to survive in test tube culture and in a natural environment as long as unmanipulated strains of the genus. Cultures of other variants, however, did not sporulate, and their viability was limited to a few months.

We can only speculate on the possibility that marine forms of the $B$. firmus $-B$. lentus complex were transferred by chance to other environments and that the hardier cells survived and their descendants became adapted to their new surroundings. Despite the futility of such speculation, the taxonomist should be alert to the possibility that strains with an unusual and seemingly dominant characteristic or strains isolated from unusual sources may be closely related to strains of long-recognized species.

This work was supported in part by grants from Novo Industri A/S, DK-2880 Bagsvaerd, Denmark and the Charles and Johanna Busch Memorial Fund. We are very grateful for this assistance and also to Drs K. Aunstrup and R. I. Nielsen of Novo Industri $\mathrm{A} / \mathrm{S}$ for the photographs.

\section{REFERENCES}

Aunstrup, K., OUtTrup, H., Andresen, O. \& Dambmann, C. (1972). Proteases from alkalophilic Bacillus species. In Proceedings of the Fourth International Symposium on Fermentation Technology Today, pp. 299-305. Edited by G. Terui. Osaka, Japan: Society of Fermentation Technology.

Boyer, E. W., Ingle, M. B. \& Mercer, G. D. (1973). Bacillus alcalophilus subsp. halodurans subsp. nov.: an alkaline-amylase-producing alkalophilic organism. International Journal of Systematic Bacteriology 23, 238-242.

Chislett, M. E. \& Kushner, D. J. (1961). A strain of Bacillus circulans capable of growing under highly alkaline conditions. Journal of General Microbiology 24, 187-190.

GoRDON, R. E. (1981). One hundred and seven years of the genus Bacillus. In The Aerobic Endosporeforming Bacteria: Classification and Identification, pp. 1-15. Edited by R. C. W. Berkeley \& M. Goodfellow. London: Academic Press.

Gordon, R. E., Haynes, W. C. \& Pang, C. H-N. (1973). The Genus Bacillus. Agriculture Handbook No. 427. Washington, D.C.: United States Department of Agriculture.

Gordon, R. E., Hyde, J. L. \& Moore, J. A., JR (1977). Bacillus firmus-Bacillus lentus: a series or 
one species? International Journal of Systematic Bacteriology 27, 256-262.

Gounot, A. M. (1967). Rôle biologique des arthrobacters dans les limons souterrains. Annales de l'Institut Pasteur 113, 923-945.

HorIKoshi, K. (1971). Production of alkaline enzymes by alkalophilic microorganisms. Part 1. Alkaline protease produced by Bacillus no. 221. Agricultural and Biological Chemistry 35, 1407-1414.

Minnikin, D. E. \& Goodfellow, M. (1981). Lipids in the classification of Bacillus and related taxa. In The Aerobic Endospore-forming Bacteria: Classification and Identification, pp. 59-90. Edited by R. C. W. Berkeley \& M. Goodfellow. London: Academic Press.

O'Donnell, A. G. \& Norris, J. R. (1981). Pyrolysis gas-liquid chromatographic studies. In The Aerobic
Endospore-forming Bacteria: Classification and Identification, pp. 141-179. Edited by R. C. W. Berkeley \& M. Goodfellow. London: Academic Press.

Priest, F. G. (1981). DNA homology in the genus Bacillus. In The Aerobic Endospore-forming Bacteria: Classification and Identification, pp. 33-57. Edited by R. C. W. Berkeley \& M. Goodfellow. London: Academic Press.

TURNER, M. \& JERVIS, D. I. (1968). The distribution of pigmented Bacillus species in saltmarsh and other saline and non-saline soils. Nova Hedwigia 16, 293-297.

VEDDER, A. (1934). Bacillus alcalophilus n. sp.; benevens enkele ervaringen met sterk alcalische voedingsbodems. Antonie van Leeuwenhoek 1, 143-147. 